\title{
14-N/15-N Metabolic Labeling Quantification
}

National Cancer Institute

\section{Source}

National Cancer Institute. 14-N/15-N Metabolic Labeling Quantification. NCI Thesaurus.

Code C161814.

A proteomic quantitation method where the samples are prepared for mass

spectrometry-based quantification by culturing the organism or cells with the heavy

nitrogen isotope, $15-\mathrm{N}$ before the sample is collected. Then the proteins are processed

and subjected to mass spectrometry-based analysis. 